\title{
Methodology of Forming the Readiness of Miners for Work in Extreme Situations Using a Training Complex
}

\author{
https://doi.org/10.3991/ijet.v15i02.11584 \\ Mikhail Krasnyanskiy, Sergey Karpushkin, Andrey Popov, \\ Artem Obukhov $\left.{ }^{(}\right)$, Denis Dedov \\ Tambov State Technical University, Tambov, Russian Federation \\ obuhov.art@gmail.com
}

\begin{abstract}
The article is devoted to the development of conceptual issues of the methodology for forming the readiness of miners for effective and safe activities in extreme situations in mines. The improvement of the efficiency of miners' training is based on using the capabilities of digital educational technologies and the developed training complex. The article defines the competency structure of workers in hazardous industries, ensuring that they perform working functions in extreme situations and reduce the risk of their life and health in case of accidents. The problem factors in the system of professional retraining are researched. The psychological and pedagogical conditions for the success of the use of the training complex are determined. The main approaches to the formation of the content of theoretical and practical training are formulated. The structure of the training complex for the training of miners is described; the process of its adjustment and functioning is considered. The key stages of the developed methodology for the formation of readiness of miners for activities in emergency situations in mines are considered. Training, using the proposed methodology and training complex, has significantly improved the application of self-rescuers, which is confirmed by an increase in the time indicator of the protective effect of the breathing apparatus used by students after training on simulators.
\end{abstract}

Keywords-Extreme situations at work, professional skill, creativity, training complex, adult education

\section{Introduction}

The work of a modern specialist quite often occurs in situations of a non-standard combination of external factors, if necessary, the performance of work in the context of restrictions on the use of material, financial and labor resources, and, most importantly, in conditions of a lack of time for making managerial decisions. The success of such activity is determined by both the specialist's necessary knowledge and skills for working with standard algorithms, and the creativity of thinking and psychological readiness to make optimal decisions in stressful situations that are characteristic of the sphere of professional activity. The willingness to work in unusual situations 
has the particular relevance for representatives of professions associated with increased risk for the employee and his colleagues.

The system of professional development aimed at workers in such industries should create the conditions for the formation of the following competency components [1]:

- Professionally oriented creativity, allowing to develop heuristic methods for solving non-standard problem situations and transfer to subsequent activities in the process of professional activity and advanced training

- Ability to conduct a comprehensive analysis of the internal and external environment of activity, adequately assess their capabilities and plan the optimal use of available resources in the current situation, including the resources of the body

- Skills of performing the simplest labor functions and activities to ensure vital functions, brought to automatism, a non-standard combination of which can solve the task

- Psychological resistance to stress, the ability to overcome psychological inertia during emergency situations

- Moral qualities, allowing to combine individual and group goals in professional activities, the dominance of man and his life as the highest value and a systemforming factor in all professional activities

The solution of the problem is complicated by the following factors:

- Existing systems of training in educational organizations and parenting in the family and the educational team quite often stops the formation of the components of ego-identity necessary for activities in extreme situations (independence, willingness to accept responsibility, creative initiative, ability for objective analysis of environment, etc.)

- Professional education is mainly focused on the acquisition by students of typical skills of the ideal flow of the production process

- Improvement of professional skills and formation of preparation for activities in extreme situations, using new technological equipment, must be organized for adults who have already taken part in the profession of specialists with certain skills and activities

- Lack of modern instrumental and pedagogical tools based on the use of the advantages of digitalization of training and allowing us to form sufficiently the necessary components of competencies; these tools should be adaptive to changing pedagogical tasks, psychological characteristics and the state of the student

- Insufficient elaboration of conceptual approaches to the formation of stress resistance while maintaining readiness for creativity and the search for non-standard ways to minimize the consequences of emergency situations

It should be noted that the use of digital pedagogical technologies should take into account the side effect of digitalization, when the line between reality and virtual space is erased; there is the possibility of re-passing any situation. The stereotype of 
"several lives", formed by an employee whose activities are related to ensuring the safety of people, can lead to irreparable consequences in real production.

The leading idea of the study concerns the development of a methodology for preparing the specialists at hazardous industries for activities in emergency situations based on the creation and use in the process of creative self-development of a training complex that is adaptive to the solved tasks will provide an increase in the level of professional skill and reduce the negative consequences from non-standard situations at work, posing a threat to the life and health of workers.

\section{$2 \quad$ Methodology}

The main methodological approaches, applied in designing a methodology for the formation of professionally important personality traits and psychological readiness using the simulator complex, are axiological, humanistic, synergetic, contextual, personal-activity, systemic.

The axiological approach [2] as a methodological basis for the formation of a specialist who is ready to resolve creatively and safely emergency situations at work for employees, considers creative professional activity as one of the leading values of the individual, team, society, which acts as a system-forming factor in the process of improving professional skill, allowing the subject of training to realize himself in the profession, develop yourself, while ensuring personal safety and the safety of the led team.

The humanistic approach [3], implemented in the development of specialist training for emergency situations, reveals the essence of the educational process aimed at developing a personality in the sense of humanism and the formation of a focus on maintaining the lives of workers as the highest value.

The synergistic approach [4] allows us to develop a strategy for the transition to heuristic and creative levels of intellectual activity of existing employees of enterprises that determine the search for a non-standard solution in case of accidents.

When developing the provisions of the methodology, we used the concept of signcontextual (contextual) training proposed by A.A. Verbitsky [5]. According to the concept of contextual education, the forms of organization of the educational activity of a person, as well as its content, should be adequate to the content and forms of practical activity of people. Contextual education as an active form of organization of educational activity approaches the forms of professional activity, and this facilitates the process of transition from learning to work. Contextual training allows you to recreate, using the simulator complex, the subject and social contexts of the professional activity of specialist industries with a high level of risk.

Particular attention is paid to the social context, as its conscious modeling in the educational process helps to solve not only the problem of improving the quality of professional training of specialists, but also educational tasks (including the organization of interaction between workers in emergency situations). The social context includes two main components such as value-orientation and personal. The valueorientation component reflects the socio-political orientation of society. The personal 
component of the social context determines the moral and ethical rules and norms of behavior in the working team and the relationship of specialists as representatives of this social system, their socio-psychological qualities and characteristics.

The problem situation in contextual education is defined as the mental state of the student's mental interaction with professionally oriented knowledge, characterized by the need for creative understanding of the information flow and the student's efforts to find a non-standard approach necessary to overcome the consequences of the accident. The inclusion of a student in a problematic situation within the context of contextual learning can be described as the state of a person coordinating his activities in the direction of creative understanding of the offered knowledge in terms of solving a professional problem [6].

We consider the process of training students for emergency situations as personality-related, while the creative development of existing specialists and the formation of psychological resistance to stress in them is the result of educational activities using the training complex.

In the context of the study, a systematic approach was implemented when considering the process of increasing professional skill in the variety of intra-systemic and super-systemic links that are essential for the tasks of the study, and, above all, identifying the leading trends and principles of the formation of psychological stability and creativity of a specialist as the basis of his competitiveness in the labor market and readiness to solve the problems of ensuring safety in industrial production.

The proposed conceptual approaches were implemented in the development of a methodology for the formation of readiness of miners for activities in extreme situations using a training complex [7-9]. The relevance of this problem is due to both the social significance of the stable work of the industry for public life, and the high level of emergency situations caused by technogenic factors and natural phenomena, and often the actions of workers, either insufficiently qualified or who violate the established safety rules.

Based on the study of the miners' activity model both during normal operation and in emergency situations, taking into account the features of the andragogy and the psychology of digital education, a set of psychological and pedagogical conditions for the successful use of the training complex to form the required components of specialist competence was determined.

As the first condition, we highlight the need to take into account the specifics of the work of miners in the development of training content in the extraction of various minerals, for example, the most dangerous situations in coal and oil mines, in potash salt mines, etc. Scenarios for the activities of specialists should take into account both working conditions (pressure, temperature, the presence of impurities and inclusions in the air), and the used technological equipment and infrastructure elements. Taking into account the possible mobility of workers and the likelihood of their transition to a sister company, it is advisable to highlight the invariant component of readiness (and the corresponding training content on the simulator) and a special one that meets the specifics of a particular educational services customer [9].

The second condition involves the creation in the learning process of various combinations of external factors during the abnormal development of events in the work- 
place and the adaptation of the program, both for educational tasks to be solved and for the psychophysiological state of the student [8]. It is especially worth emphasizing that students' awareness of the complete impossibility of completing the assigned working task and optimally using the available resources, including the resources of the body, can inhibit all creative processes and create a steady fear of the probability of activity in extreme situations. In the process of completing tasks on the simulator, the gap between the necessary efforts to complete the task and the demonstrated level of readiness of the learner should be significant, but not critical. The designed production situation should allow the student with the maximum concentration of efforts to find the optimal way to solve the problem. Therefore, the training process should begin with the formation of skills for safe and productive activities when working in a planned mode, then focus on the formation of behavior skills in the most common emergency situations (the algorithm of activity in which has been tested by time), and only at the final situation with the help of software the improbable (because of this they are more dangerous) emergency situations are designed that allow you to reach the heuristic level of intellectual activity while maintaining psychological stability.

The third condition for the use of the training complex involves the period of adaptation of the student to the conditions of virtual reality and the periodic stages of reflection of activity to overcome the psychological imbalance between solving educational problems and real production problems that a production specialist will face [10].

In order to overcome psychological deformation and relieve internal stress among students, it is necessary during the training process to alternate tasks that require clear fulfillment of labor functions and safety rules, and problem situations associated with the occurrence of industrial emergencies. The pulsed nature of the pedagogical impact when using the simulator is the fourth psychological and pedagogical condition. Therefore, training begins with preparation for activities in regular situations, and then the percentage of tasks that require a creative approach from a specialist, concentration of all spiritual and physical forces, implying increased responsibility for the production result and the life and health of the staff, and of course the employee himself, gradually increases.

Training with the simulator is preceded by enhanced theoretical training of staff [10-12]. Five modules can be distinguished in it:

- Study of the possibilities of technological equipment and infrastructure elements, rarely used in regular situations

- Determination of reserves of one's own body, planning corrective measures to improve physical fitness

- Overcoming the psychological inertia and the development of imagination, innovative thinking, independence

- Approaches and trainings for the formation of resistance to stressful situations, the ability to analyze information during a period of psychological stress and make informed decisions in a limited period of time 
- Analysis of accidents that have already occurred in mines of different degree of complexity and scope of consequences, study of personnel activities and identification of errors or gaps in preparation

For the organization of training using the simulator, the training material applied for theoretical training of personnel is prepared, professional activity is modeled, and the content of training is determined in the form of a passport of competencies generated by various tasks [13].

Based on the analysis of the subject area, a mathematical model of the technical system is formed, in this case, the mine. This model includes a formalized representation of the main objects of the mine, the processes of their interaction, as well as a description of the physical processes taking place in this technical system. In order to implement training scenarios both in regular and emergency modes of personnel work, it is necessary to analyze the model of personnel (students) activities. Having thus developed a set of training scenarios, one can proceed to the implementation of the visualization system taking into account the selected tools and technologies. The designed visualization system should take into account and implement all aspects of the students' activities under various operating modes, as well as in emergency situations [14-16].

After the implementation of the visualization system, it is possible to adjust it taking into account the individual characteristics of students, their mental and physical parameters.

The configured simulator is checked by a test run, during which the correct functioning of all subsystems is confirmed at the specified settings and selected training scenarios.

\section{$3 \quad$ Results}

We will directly consider the methodology for forming the readiness of miners for emergency activities in mines.

At the first stage, personnel are trained to work with the training complex (Fig. 1). This stage is aimed at developing the appropriate competencies for students in the field of simulator ownership, which ensures them successful training on such systems.

Initially, students learn the structure of virtual reality helmets and gain practical skills in working with them. This is necessary, first of all, for adapting the student's body (vision, vestibular apparatus) to the specifics of working in helmets of virtual reality.

Next, training is given to work with the controllers of the training complex; their structure and the purpose of the control elements are studied. Practical exercises are carried out to maintain a number of operations in virtual reality using controllers. 


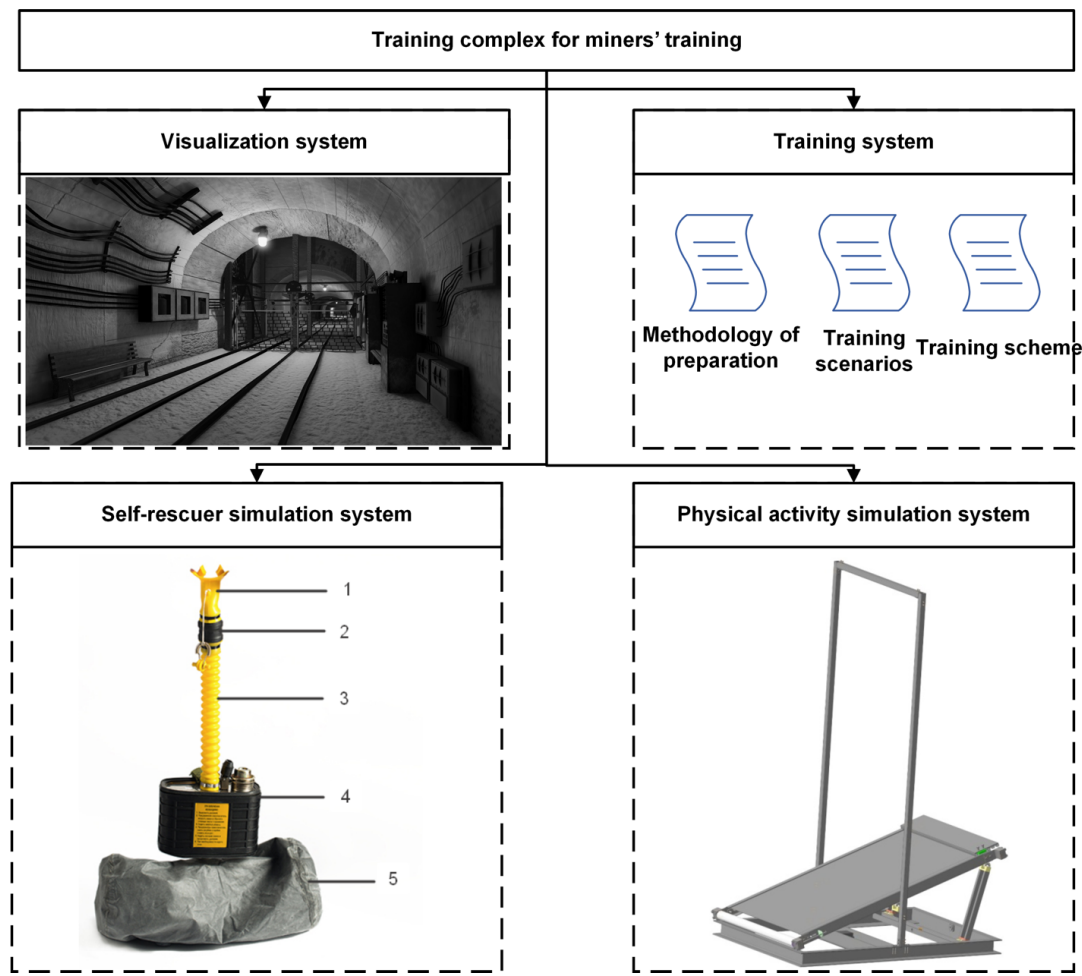

Fig. 1. Structure of training complex for miners' training

The next stage is the adaptation of students to work on a simulator of physical activity, for example, a treadmill. This type of simulators requires some preparation so that the student can fully and confidently perform exercises, maintaining balance. The functioning of the treadmill is based on the operation of the accelerometer, as at this stage, the student also needs to develop practical skills for working on the simulator in order to understand and master the principles of movement in virtual reality using simulators. Also, students use a self-rescuer simulator to develop practical skills in the correct breathing process in various conditions, both during activity and in a calm state.

At the second stage, the development of skills of mine personnel in normal conditions is carried out. At this stage, the student, who mastered the basic principles of working on the simulator and developed a certain level of practical skills in it, proceeds directly to training on the given scenarios of the normal operation of the enterprise.

The next stage of training is the development of practical skills in emergency situations - fires, smoke, flooding, collapse, lack of visibility and light sources, etc. Situations are modeled by controlling the simulator of physical activity and the corresponding scenarios of the visualization subsystem of the training complex.

An important stage in the methodology is the data collection, processing and analysis on the status of students in the process of forming readiness for activity in emer- 
gency situations. Also, during the training, the readings of various sensors are collected - pulmonary activity, cardiac sensors, indicators of pressure, pulse, etc. Using the selected methods for assessing the human condition, the collected data are analyzed and recommendations are made for the learning process improvement. Those components of competencies that were not mastered by the student will be worked out with greater intensity at the next iteration of the learning process $[10,17]$.

Based on the learning process monitoring, a final report is generated containing all the information about:

- Results of mastering the theoretical program by each student

- Results of preparation for work on the simulator

- Results of the test tasks during the training scenarios mastering in regular and emergency situations at each iteration of training

- Dynamics of changes in the components of competence, readiness for activity in non-standard situations, psychological stability

- Quantitative and qualitative assessments of psychophysiological state of students before and after the start of the learning process

Using the obtained information, it is possible to organize an effective and adaptable process of training mine personnel in various working conditions that adapts to individual characteristics.

The experimental studies were carried out according to the following scheme. Physical activity was modeled using a treadmill with a given speed and tilt angles. The student was immersed in virtual reality using OculusRiftDK2 virtual reality helmet and 3D model of the mine named after Kirov. The tests consisted of 3 stages.

Stage 1 - assessment of the physical condition of the student. This stage is applied at the initial stage of training and is carried out once during the entire cycle of training and retraining.

At this stage, the student's breathing efficiency is evaluated by conducting a test exit from the mine at the training complex. The assessment is carried out by a medical worker evaluating the data obtained (pneumotachograms, spirograms, pulsograms and control measurements of blood pressure). The test output lasts 60 minutes and is divided into 3 stages of 20 minutes. The tilt angle of the treadmill is: 1.1 stage - 0 degrees, 1.2 stage - 12 degrees, 1.3 stage - 4 degrees. The speed of 10 minutes is $4 \mathrm{~km} / \mathrm{h}$ and 10 minutes is $5 \mathrm{~km} / \mathrm{h}$ for steps 1.1 and 1.2 , respectively, the speed is set as follows for step 1.3: 4 minutes at a speed of $7 \mathrm{~km} / \mathrm{h}, 1$ minute at a speed of $10 \mathrm{~km} / \mathrm{h}, 5$ minutes at a speed of $5 \mathrm{~km} / \mathrm{h}, 10$ minutes at a speed of $8 \mathrm{~km} / \mathrm{h}$. The data, obtained as a result of testing, are studied, on the basis of which a conclusion is made about contraindications and the possibility of further training.

The second stage of training: At this stage, training in effective breathing is carried out using a self-rescuer simulator SHSS-TM. The initial training modes are determined on the basis of data obtained after the first stage. Depending on the values of pulmonary ventilation, the student begins with a different sub-step: 2.1 (low results), 2.2 (average results), 2.3 (high results). 
In the learning process, there is a periodic change in the speed of movement within 3-6 km/h, which corresponds to slow and fast walking, with a periodic transition to running at a speed of $7-10 \mathrm{~km} / \mathrm{h}$.

The learning process is carried out with alternating physical activity mode. Moreover, if the student on any segment has a sharp shift in the parameter of pulmonary ventilation from the initial to the final or beyond the norm, then it is necessary to reduce the speed or decrease the inclination angle.

The duration of training at the second stage is from 3 to 15 cycles for each substage 2.1-.2.3, the number of training cycles is determined by the results of 3 previous cycles. If, during 3 cycles, the student demonstrates the values of pulmonary ventilation and the time of protective action (TPA), then we can proceed to the next stage of training.

The third stage is testing on a sample of SHSS-TM self-rescuer. Testing is carried out at the training complex, a virtual mine section is used for this. In order to successfully pass the test, the student must overcome a mine section of $2 \mathrm{~km}$ in 1 hour. At the same time, at the end of the route, the device must remain operational, i.e. the breathing bag should not collapse, and the temperature of the respiratory mixture should not cause severe discomfort.

The results of the training of miners in the third stage are presented in Table 1 and reflect the change in TPA when using self-rescuers due to the development of the right breathing skills.

Table 1. Results of miners training using IBA simulation system

\begin{tabular}{|c|c|c|c|c|}
\hline $\begin{array}{c}\text { Student's } \\
\text { number }\end{array}$ & $\begin{array}{c}\text { Number of training } \\
\text { cycles (2.1/2.2/2.3) }\end{array}$ & $\begin{array}{c}\text { TPA before training, } \\
\text { minutes }\end{array}$ & $\begin{array}{c}\text { TPA after } \\
\text { training, minutes }\end{array}$ & $\begin{array}{c}\text { Increase of TPA, } \\
\text { \% }\end{array}$ \\
\hline 1. & $14 / 12 / 15$ & 19 & 32 & 68 \\
\hline 2. & $9 / 11 / 12$ & 27 & 41 & 52 \\
\hline 3. & $11 / 12 / 12$ & 24 & 40 & 67 \\
\hline 4. & $14 / 13 / 14$ & 21 & 32 & 52 \\
\hline 5. & $0 / 3 / 5$ & 32 & 46 & 44 \\
\hline 6. & $7 / 6 / 8$ & 26 & 37 & 42 \\
\hline 7. & $10 / 12 / 11$ & 20 & 31 & 55 \\
\hline 8. & $14 / 15 / 15$ & 17 & 32 & 88 \\
\hline 9. & $3 / 5 / 6$ & 27 & 35 & 30 \\
\hline 10. & $6 / 6 / 9$ & 24 & 34 & 42 \\
\hline
\end{tabular}

We present the obtained experimental data graphically in the form of a diagram (Fig. 2). 


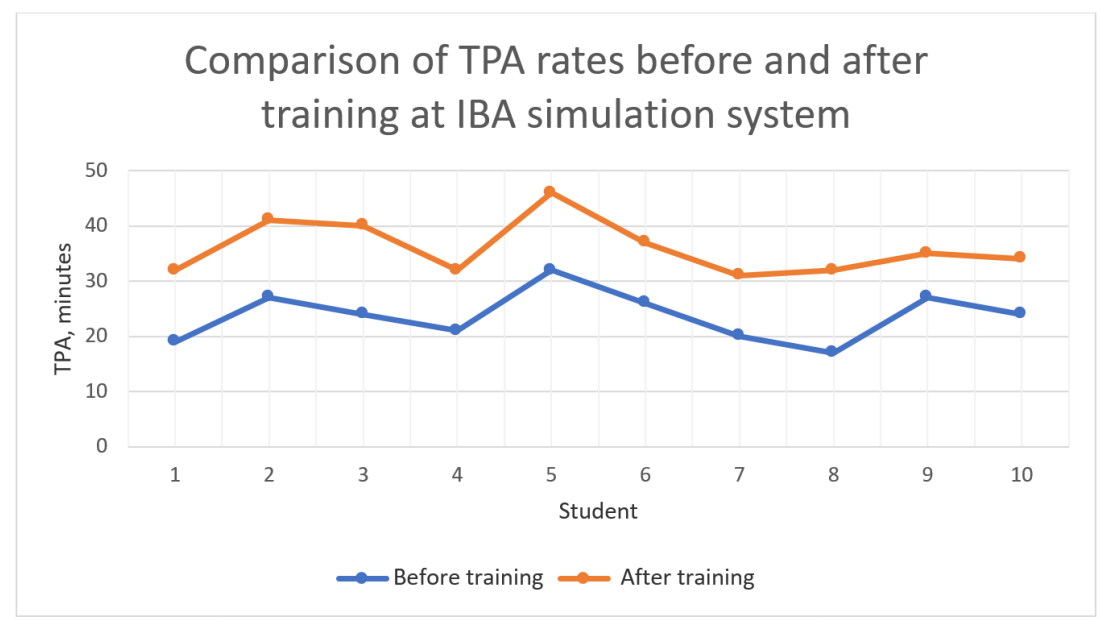

Fig. 2. Change of TPA indicators after training

A positive effect can be noted, the magnitude of which depends on the physical characteristics of the person and his initial preparation. There is the following pattern if the student is less trained and has worse results (lack of proper breathing skills), the effect of using IBA simulation system is more noticeable.

\section{Conclusion}

The article defines the competency structure of workers in hazardous industries, ensuring that they perform labor functions in extreme situations and reduce the risk of their life and health in case of accidents.

The conceptual approaches to the organization of the process of professional development of employees aimed at creating readiness for effective work in extreme situations are developed. The psychological and pedagogical conditions for the success of the use of the training complex are determined. The main approaches to the formation of the content of theoretical and practical training are formulated.

Based on the proposed methodological approaches, a methodology was developed to form the readiness of miners to work in emergency situations in mines.

The process of adjustment and functioning of the mine training complex, including the process of training and adaptation, is studied. The developed simulator complex allows, in accordance with various training scenarios, representing a given sequence of actions and possible solutions to specific problems, conducting training and creative self-development of mine personnel.

In the course of experimental studies, a training technology using a simulator complex was developed and tested that takes into account the specifics of a particular production facility and includes several stages. The possibility of adaptive management of the learning process depending on the successful completion of each stage or exercise by students is determined. 
The experimental studies of the effectiveness of the use of the training complex to improve professional skills and the formation of preparation for activities in nonstandard and emergency situations were carried out. Training, using the proposed methodology and training complex, has significantly improved the use of selfrescuers, which is confirmed by the increase in TPA rate in the focus group after training on simulators.

The results of the research can be used to improve the educational process for the formation of professionally important qualities based on digital technologies. The construction of the educational process on the basis of the developed methodology and when using the simulator complex provides advanced training for workers in the mining industry and the formation of their readiness for professional activity in difficult external conditions, as well as in the event of extreme and emergency situations.

\section{Acknowledgement}

The reported study was funded by RFBR according to the research project № 19013-00567 on the basis of "Digital Engineering" collective use center.

\section{References}

[1] Yue, H., Cai, K., Yu, Y., He, Y., \& Jin, Y. (2017). Investigation and Analysis of College Students' Cognition in Science and Technology Competitions. International Journal of Emerging Technologies in Learning (iJET), 12(07), 146-157. https://doi.org/10.3991/ijet. v12i07.7226

[2] Audebrand, L. K., \& Pepin, M. (2019, July). Principles for Responsible Management Education: A Value-Driven Approach. In Academy of Management Proceedings (Vol. 2019, No. 1, p. 12887). Briarcliff Manor, NY 10510: Academy of Management. https:// doi.org/10.5465/ambpp.2019.179

[3] Ewin, N., Luck, J., Chugh, R., \& Jarvis, J. (2017). Rethinking project management education: a humanistic approach based on design thinking. Procedia Computer Science, 121, 503-510. https://doi.org/10.1016/j.procs.2017.11.067

[4] Petrenko, M. A. (2015). The developmental interactive technology of students' creative activity. Open Science Journal of Education, (3), 43-47.

[5] Verbickij, A. A. (1991), Aktivnoe obuchenie v vysshej shkole: kontekstnyj podhod, Vysshaya shkola, 204.

[6] Petrova, T. N., Kirillova, O. V., Sokolova, S. G., Pugacheva, N. B., Galimullina, A. F., Maksimova, O. G., ... \& Kozhanov, V. V. (2016). Education as the management of research universities students' socialization. International Review of Management and Marketing, 6(2S), 28-33.

[7] Alexander, B., \& Vladislav, B. (2016). Educational technology for teaching survival skills to pilots using training routines. Journal of Physical Education and Sport, 16(2), 413.

[8] Kozina, Z. L., \& Iermakov, S. S. (2015). Analysis of students' nervous system's typological properties, in aspect of response to extreme situation, with the help of multidimensional analysis. Physical education of students, 19(3), 10-19. https://doi.org/10.15 $\underline{561 / 20755279.2015 .0302}$ 
[9] Meshcheryakov, A. V. (2017), Predposylki sozdaniya i trebovaniya k razrabotke teorii deyatel'nosti cheloveka $\mathrm{v}$ ekstremal'nyh situaciyah, Ekstremal'naya deyatel'nost' cheloveka, (1), 9-13.

[10] Krasnyanskiy, M., Obukhov, A., Dedov, D., \& Siukhin, A. (2018). Modeling of the learning process in adaptive training complexes. Journal of Applied Engineering Science, 16(4), 487-493. https://doi.org/10.5937/jaes16-17627

[11] Gao, C., \& Wu, Q. (2017). Design and Practice of Surveying Experiment System based on a Virtual Platform. International Journal of Emerging Technologies in Learning (iJET), 12(4), 53-61. https://doi.org/10.3991/ijet.v12i04.6924

[12] Gavish, N., Gutiérrez, T., Webel, S., Rodríguez, J., Peveri, M., Bockholt, U., \& Tecchia, F. (2015). Evaluating virtual reality and augmented reality training for industrial maintenance and assembly tasks. Interactive Learning Environments, 23(6), 778-798. https://doi.org/10. $\underline{1080 / 10494820.2013 .815221}$

[13] Wang, X., Hao, Z., Luo, S., \& Ren, M. (2018). A Teaching Model of Urban and Rural Planning Curriculum Integrating Virtual Simulation Technology. International Journal of Emerging Technologies in Learning (iJET), 13(6). https://doi.org/10.3991/ijet.v13i06.8584

[14] Lou, M. (2017). A Virtual Reality Teaching System for Graphic Design Course. International Journal of Emerging Technologies in Learning (iJET), 12(09), 117129. https://doi.org/10.3991/ijet.v12i09.7492

[15] Guo, H. (2016). Application of Virtual Reality Technology in Swimming Teaching. International Journal of Emerging Technologies in Learning (iJET), 11(11), 9-14.

[16] Cao, F. (2016). A ship driving teaching system based on multi-level virtual reality technology. International Journal of Emerging Technologies in Learning (iJET), 11(11), 26-31. https://doi.org/10.3991/ijet.v11i11.6249

[17] Dedov, D., Alexeev, S., Zakharov, A., Sidorchuk, A., \& Arhipov, A. (2018). Virtual training complex for breathing skills practice in self-rescuers. International Multidisciplinary Scientific GeoConference: SGEM: Surveying Geology \& mining Ecology Management, 18 , 1021-1027. https://doi.org/10.5593/sgem2018/1.3/s03.128

\section{Authors}

Mikhail Krasnyanskiy is a rector of Tambov State Technical University, Tambov, Russian Federation. Professor, Doctor of technical sciences degree in Processes and Apparatuses of Chemical Technologies.

Sergey Karpushkin is a Professor of the Department "Computer-integrated systems in mechanical engineering" in Tambov State Technical University, Tambov, Russian Federation. Doctor of technical Sciences.

Andrey Popov is a candidate of pedagogical Sciences, associate Professor of the Department "Technique and technology of production of nanoproducts" in Tambov State Technical University, Tambov, Russian Federation

Artem Obukhov is a senior researcher, senior lecturer in Department of Automated Systems of Decision-Making Support in Tambov State Technical University, Tambov, Russian Federation. PhD in engineering.

Denis Dedov is a senior researcher in Tambov State Technical University, Tambov, Russian Federation. PhD in engineering. Director of the center for collective use "Digital engineering" (Tambov).

Article submitted 2019-08-28. Resubmitted 2019-10-05. Final acceptance 2019-10-05. Final version published as submitted by the authors. 